\title{
Article \\ Chemical and Sensorial Characterization of Scented and Non-Scented Alstroemeria Hybrids
}

\author{
Danilo Aros ${ }^{1, *}$, Macarena Suazo ${ }^{1}$, Marcela Medel ${ }^{1}$ and Cristina Ubeda ${ }^{2,3}$ \\ 1 Facultad de Ciencias Agronómica, Universidad de Chile, Santiago 8820808, Chile; \\ msbriones@hotmail.com (M.S.); mmedel@uchile.cl (M.M.) \\ 2 Departamento de Nutrición y Bromatología, Toxicología y Medicina Legal, Facultad de Farmacia, \\ Universidad de Sevilla, C/Profesor García Gonzalez 2, 41012 Sevilla, Spain; c_ubeda@us.es \\ 3 Instituto de Ciencias Biomédicas, Universidad Autónoma de Chile, Santiago 8380000, Chile \\ * Correspondence: daros@uchile.cl; Tel.: +56-2-2978-5728
}

check for updates

Citation: Aros, D.; Suazo, M.; Medel, M.; Ubeda, C. Chemical and Sensorial Characterization of Scented and Non-Scented Alstroemeria

Hybrids. Horticulturae 2022, 8, 65 . https://doi.org/10.3390/ horticulturae 8010065

Academic Editor: Luigi De Bellis

Received: 1 December 2021

Accepted: 31 December 2021

Published: 10 January 2022

Publisher's Note: MDPI stays neutral with regard to jurisdictional claims in published maps and institutional affiliations.

Copyright: (C) 2022 by the authors. Licensee MDPI, Basel, Switzerland. This article is an open access article distributed under the terms and conditions of the Creative Commons Attribution (CC BY) license (https:// creativecommons.org/licenses/by/ $4.0 /)$.

\begin{abstract}
Floral scent plays an important ecological role attracting pollinators. Its composition has been elucidated for a vast diversity of species and is dominated by volatile organic compounds (VOCs) such as monoterpenoids, sesquiterpenoids, phenylpropanoids and benzenoid compounds. Considering that floral scent is also an important character for the ornamental plant market, this study was aimed at characterizing and comparing the molecular composition of scented and non-scented alstroemeria flowers. Confirmation of floral scent was performed through sensorial analysis, while GC-MS analysis detected monoterpenes and esters as major volatile organic compounds (VOCs). A total of 19 and 17 VOCs were detected in the scented hybrids 13M07 and 14E07, respectively. The non-scented hybrid 13B01 shared 14 VOCs with the scented hybrids, although it showed different relative concentrations. Comparison between scented and non-scented hybrids suggests that diversity and amounts of VOCs are likely due to the ecological role of scent, while the human perception of floral scent is not strictly related to the VOC profile.
\end{abstract}

Keywords: floral scent; sensorial analysis; GC-MS; alstroemeria; monoterpenes; methyl benzoate; methyl salicylate

\section{Introduction}

It is well known that the main function of floral scent is to attract pollinators [1], playing an important role in the idea of 'pollination syndrome' described in nature [2]. However, it is not completely clear how floral scent has the ability to attract specific pollinators, as it is for other visual cues such as flower morphology and colour [3,4]. Many other functions have been attributed to floral scent, including the emission of certain compounds with the aim of repelling non-beneficial insects, for example, pollen and nectar 'thieves' or destructive insects [5]. Protection of reproductive organs from enemies through antimicrobial or antiherbivore activity attributed to some of the floral scent compounds have also been studied [6-8]. More recently, it was discovered that floral volatiles could function as cues to other plants, using them to gain information about their environment and respond by adjusting their phenotype [9].

The composition of aroma has been studied in a vast diversity of species, finding different molecular compositions in terms of number and characteristic of the molecules involved in the scent [10]. Moreover, floral scent emission has been identified to respond to several factors such as light [11], temperature [12] and concentration of ozone in the air [13]. To determine the composition of the floral scent, the most widely used technique is gas chromatography coupled with a mass detector (GC-MS), finding that floral scent is dominated by volatile organic compounds (VOCs) such as monoterpenoids, sesquiterpenoids, phenylpropanoids and benzenoid compounds [5]. Thus, a total of 1719 VOCs have been identified as composing the floral scent of 991 species [14]. An electronic nose has also 
been useful to determine floral scent patterns in flowering stages [15]. However, not only instrumental evaluation has been described to evaluate floral scent; recent studies have also considered sensorial evaluation $[16,17]$ as a complement to a better understanding of this character.

This study is focused on the evaluation of scent emitted by flowers of alstroemeria hybrids. The genus Alstroemeria is native to South America and comprises 90 species [18], of which only one has been described as aromatic: A. caryophyllaea Jacq. [19]. Many new cultivars have been developed, and nowadays alstroemeria is one of the most important species in the market of ornamental plants, especially as cut flowers [20], and more recently as pot plants [21]. However, floral scent is not a character that breeders have been particularly focused on, probably because this is a complex trait to breed, easily acquired and lost throughout generations [22]. Moreover, a negative correlation between the presence of floral scent and shorter vase life of the flower has been suggested. [23]. The floral scent of alstroemeria has been previously studied in the wild species $A$. caryophyllaea Jacq., the cultivars 'Sweet Laura' and 'Ajax' [24], and several hybrids [16,25] reporting terpenoid compounds as the most common VOCs detected, particularly monoterpenes. Moreover, a monoterpene synthase (AlstroTPS) has been characterised as responsible for the production of myrcene in alstroemeria flowers [24], being the only gene associated to floral scent reported so far in this species.

Although floral scent of alstroemeria has already been described in some alstroemeria genotypes, as previously described, this is a very dynamic character that changes throughout generations. Thus, the aim of this study was focused on the characterization of the molecular composition of the scent of two new scented alstroemeria hybrids, resulting from crosses using A. caryophylleae as parental line.

\section{Materials and Methods}

\subsection{Plant Material}

A total of 18 alstroemeria hybrids grown under greenhouse conditions at the Faculty of Agricultural Sciences, maintained at 15 to $25^{\circ} \mathrm{C}$ and $>40 \% \mathrm{HR}$ and a natural photoperiod of 15 to $16 \mathrm{~h}$ of light (Santiago, Chile, $33^{\circ} 34^{\prime} 11^{\prime \prime} \mathrm{S} 70^{\circ} 37^{\prime} 50^{\prime \prime} \mathrm{W}$ ). Hybrids from cross pollinations performed during 2013 and 2014, were analysed (Appendix A). For the sensorial analysis, flowers were evaluated at the greenhouse, while for the GC-MS evaluation, individual flower stems were collected, trimmed to $3 \mathrm{~cm}$, placed individually into 20-mL glass jars and directly analysed.

\subsection{Sensorial Confirmation of Scented Hybrids}

To confirm the presence and assess the intensity of floral scent, 18 alstroemeria hybrids were analysed through sensorial evaluation performed by a 'non-trained' panel composed of six individuals, considered as replicates, including males and females with no restriction on age. They were recruited via email and using advertising posters, and their participation was voluntary. Individuals were asked to answer the question 'Does this flower have a scent?', and the possible answers were 'yes' or 'no'. In order to assess possible floral scent output fluctuation due to circadian rhythm and/or flowering stage, the analysis was performed three times during the day (10:00 a.m., 1:00 p.m. and 4:00 p.m.) and at three different stages of development (S3, S4 and S5 [26]; Appendix B). Each evaluator was considered as a replicate, and the results were converted into numbers (yes $=1$ and no $=0$ ) for statistical analysis.

For those hybrids considered to be scented in this first evaluation, a second sensorial analysis was performed by a trained panel composed of 12 individuals, considered as replicates, to assess floral scent intensity. This analysis was performed at stage 4 , between 1:00 p.m. and 4:00 p.m. (average stage and time of maximum floral scent output) and the individuals were asked to evaluate floral scent by following the scale: 'extremely high'; 'very high'; 'moderately high'; 'slightly high'; 'neither high nor low'; 'slightly low'; 
'moderately low'; 'very low'; and 'extremely low'. Results were converted into numbers (extremely high $=9$ and extremely low $=1$ ) for statistical analysis.

\subsection{Evaluation of Scent Composition of Scented Alstroemeria Hybrids through GC-MS}

Flowers of alstroemeria hybrids confirmed to be scented by the sensorial analysis (13M07 and 14E07), plus a confirmed non-scented hybrid (13B01) used as a control, were analysed through GC-MS. This analysis was performed using three replicates and each replicate consisted of one single flower at stage 4 taken from different inflorescences of the same plant, between 1:00 p.m. and 4:00 p.m. (average stage and time of maximum floral scent output) with the following protocol.

The extraction of the volatile compounds was done through Solid Phase Microextraction technique (SPME) with a triple fibre of Divinylbenzene/Carboxen/Polydimethylsiloxane (DVB/CAR/PDMS) (StableFlex fiber, Sigma-Aldrich, Gillingham, UK) which was exposed for $15 \mathrm{~min}$ to the headspace of $20 \mathrm{~mL}$ flasks containing the flower with a penetration of $21 \mathrm{~mm}$. The incubator was set at $45^{\circ} \mathrm{C}$ and afterwards the fibre was desorbed for $180 \mathrm{~s}$ at $280{ }^{\circ} \mathrm{C}$. Gas chromatography analysis was carried out using a 7890B Agilent GC system coupled to a quadrupole mass spectrometer Agilent 5977 inert (Agilent Technologies, Palo Alto, CA, USA) and employing a DB Wax capillary column $(60 \mathrm{~m} \times 0.25 \mathrm{~mm}$, and $0.25 \mu \mathrm{m}$ film thickness $)$ (J\&W Scientific, Folsom, CA, USA) using helium as the carrier gas at a flow rate of $1 \mathrm{~mL} / \mathrm{min}$. The oven temperature program started at $35^{\circ} \mathrm{C}$ for $1 \mathrm{~min}$ increasing to $130{ }^{\circ} \mathrm{C}$ at $12{ }^{\circ} \mathrm{C} / \mathrm{min}$ and held for $1 \mathrm{~min}$, then to $160{ }^{\circ} \mathrm{C}$ at $1{ }^{\circ} \mathrm{C} / \mathrm{min}$, and then to $220^{\circ} \mathrm{C}$ at $10^{\circ} \mathrm{C} / \mathrm{min}$ (held for $10 \mathrm{~min}$ ). Electron ionization mass spectra in the scan mode were recorded at $70 \mathrm{eV}$ with the electron energy in the range of 35 to $300 \mathrm{amu}$.

A solution of $10 \mu \mathrm{L}$ of 4-methyl-2-pentanol ( $0.75 \mathrm{mg} / \mathrm{L}$ ) Merck (Darmstadt, Germany) in ethanol was used as an internal standard to check the correct operation of the equipment and the use of the fibre. For calculation of retention (Kovats) indices, a solution of alkanes $\left(C_{7}-C_{30}\right)$ was injected under the same conditions as described for the samples.

The peaks displayed in the chromatograms were analysed with an MS ChemStation (Agilent Technologies, Palo Alto, CA, USA). Identification was performed by comparing mass spectra of each compound with the NIST Library (ver. 1.2.) and with the Kovats index found in the literature, Flavornet, Pherobase and NIST Mass Spectrometry Data Center. A total of three biological replicates were performed. Semi-quantification was performed in terms of absolute areas and the standard deviation for each replicate was also calculated.

\subsection{Statistical Analysis}

Data obtained from the sensorial analysis and the evaluation of scent composition through GC-MS were subjected to an analysis of variance (ANOVA). Means were compared using Fishers least significant difference (LSD) test for multiple pair-wise comparisons with a significance level of 0.05 . These statistical analyses were performed using InfoStat software.

\section{Results}

\subsection{Sensorial Confirmation of Scented Hybrids}

In the sensorial analysis the hybrids $13 \mathrm{M} 07$ and 14E07 were the two genotypes assessed as consistently scented, in comparison with other hybrids where scent was perceived rarely or as absent by the evaluators. Both hybrids come from the cross between the native species A. pelegrina and the scented A. caryophyllaea line 0276-02 (Figure 1). On the other hand, the hybrid 13B01, despite having a scented line as parental line (UC-05) (Figure 1), was consistently assessed as 'non-scented' by the evaluators and was used as a negative control. 


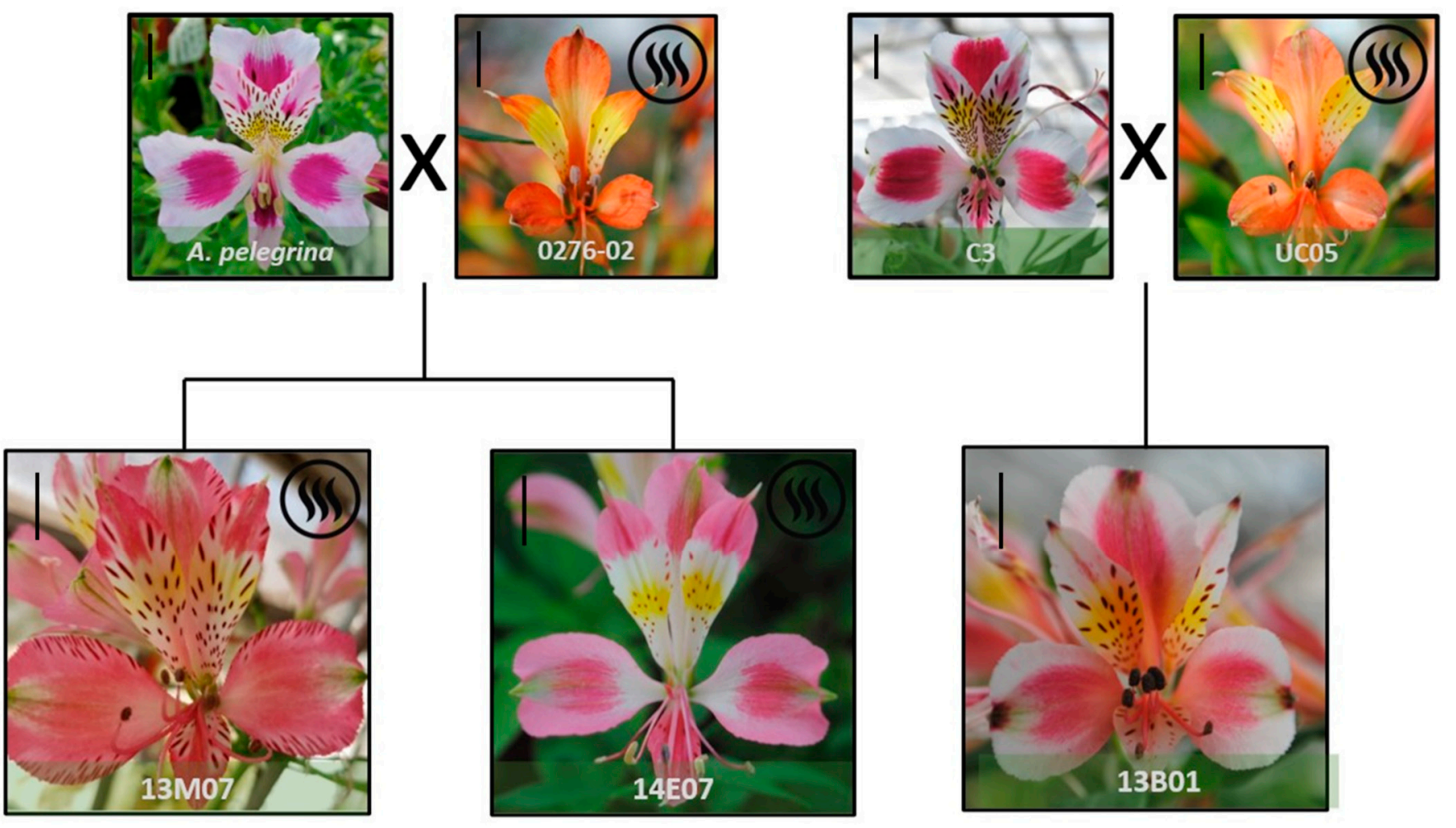

Figure 1. Scented (13M07 and 14E07) and non-scented (13B01) alstroemeria hybrids evaluated, showing their pedigree and floral morphology at stage $S 4$ [26]. A scale bar $(=1 \mathrm{~cm})$ is included on the left upper corner of each picture.

Interactions between the factors evaluated were statistically significant. Thus, there was an effect of the stage of development and the time of evaluation on the perception of floral scent. While the hybrid 13M07 was fully perceived as scented $(>0.5)$ in all the stages of development and all the times of evaluation, 14E07 was mainly perceived as scented at stages S4 and S5 and during the afternoon (1:00 p.m. and 4:00 p.m.). On the other hand, the hybrid 13B01 was consistently perceived as 'non-scented', except when the sensorial analysis was performed at 4:00 p.m., when only a few evaluators considered this hybrid as scented (Table 1).

Table 1. Summary of the averages obtained for the sensorial analysis of floral scent perceived in alstroemeria (yes $=1$ and no $=0$ ) at different stages of development and different times of evaluation. Values for the intensity of the floral scent (extremely high $=9$ and extremely low $=1$ ) are shown for the scented hybrids.

\begin{tabular}{cccccccc}
\hline \multirow{2}{*}{ Hybrid } & \multicolumn{3}{c}{ Stage of Development } & \multicolumn{3}{c}{ Time of Evaluation (h) } \\
\cline { 2 - 6 } & S3 & S4 & S5 & $\mathbf{1 0 : 0 0 ~ a . m . ~}$ & $\mathbf{1 : 0 0 ~ p . m . ~}$ & 4:00 p.m. & Intensity \\
\hline 13M07 & 0.50 & 0.68 & 0.68 & 0.50 & 0.61 & 0.75 & $3.58^{\mathrm{a}, *}$ \\
14E07 & 0.00 & 1.00 & 0.68 & 0.00 & 0.50 & 1.00 & $7.11^{\mathrm{b}}$ \\
13B01 & 0.00 & 0.00 & 0.00 & 0.00 & 0.00 & 0.27 & $\mathrm{ni}^{* *}$ \\
\hline
\end{tabular}

* Different letters indicate significant differences in ANOVA followed by a Fisher LSD test $(p \leq 0.05)(n=12)$

** No information.

Floral scent intensity was evaluated as higher for the hybrid 14E07, with an average value of 7.11 ('moderately high'), in comparison with hybrid 13M07 that showed a mean value of 3.58 ('slightly low') (Table 1). 


\subsection{Evaluation of Scent Composition of Scented Alstroemeria Hybrids through GC-MS}

A total of 19 VOCs were detected as part of the floral scent of the hybrid 13M07, of which hexanal, methyl octanoate and cyclosativene were not identified in 14E07, which was also scented. The non-scented hybrid 13B01 shared 15 VOCs with the scented hybrids, although it showed different amounts in terms of absolute peak areas. The ester methyl salicylate $(=6,075,487)$ detected in the floral scent of the hybrid 13M07 showed significant differences compared with the presence of this ester in the hybrids 13B01 $(=50,712)$ and 14E07 $(=298,455)$. On the other hand, the monoterpene (E)-ocimene showed no differences between the hybrids. From the 19 VOCs detected in 13M07, 11 of them showed amounts significantly higher in comparison with the other two alstroemeria hybrids (Table 2).

Table 2. Floral scent composition of scented (13M07 and 14E07) and non-scented (13B01) alstroemeria hybrids, showing the Retention Index (RI), system of identification (ID), aromatic description and amount (peak area expressed in arbitrary units).

\begin{tabular}{|c|c|c|c|c|c|c|}
\hline \multirow{2}{*}{ VOCs } & \multirow{2}{*}{ RI } & \multirow{2}{*}{ ID * } & \multirow{2}{*}{$\begin{array}{c}\text { Aromatic } \\
\text { Description ** }\end{array}$} & \multicolumn{3}{|c|}{ Alstroemeria Hybrid } \\
\hline & & & & 13M07 & 13B01 & 14E07 \\
\hline Hexanal & 1081 & A & Grass, tallow, fat & $39,871 \pm 2814^{c, * * *}$ & $11,020 \pm 2094^{b}$ & nd $^{a, * * * *}$ \\
\hline$\beta$-Pinene & 1127 & A & $\begin{array}{l}\text { Pine, resin, } \\
\text { turpentine, wood }\end{array}$ & $12,055 \pm 630^{\mathrm{b}}$ & $1475 \pm 146^{\mathrm{a}}$ & $14,942 \pm 476^{c}$ \\
\hline Methyl hexanoate & 1168 & A & Fruit, fresh, sweet & $47,155 \pm 3531^{c}$ & $32,435 \pm 472^{b}$ & $13,558 \pm 545^{\mathrm{a}}$ \\
\hline D-Limonene & 1187 & $\mathrm{~A}$ & Lemon, orange & $33,905 \pm 3045^{c}$ & $6098 \pm 838^{a}$ & $18,832 \pm 3847^{b}$ \\
\hline Eucalyptol & 1212 & $\mathrm{~B}$ & $\begin{array}{l}\text { Pine, eucalyptus, } \\
\text { herbal, camphor }\end{array}$ & $154,172 \pm 16,341^{c}$ & $16,454 \pm 1588^{a}$ & $110,033 \pm 1239^{b}$ \\
\hline (Z)-Ocimene & 1234 & A & Citrus, herb, flower & $95,447 \pm 11,786^{\mathrm{a}}$ & $55,464 \pm 23,0444^{a}$ & $102,730 \pm 21,584^{a}$ \\
\hline (E)-Ocimene & 1249 & A & Sweet, herb & $1,142,285 \pm 450,187^{a}$ & $689,933 \pm 369,096^{a}$ & $707,495 \pm 343,866^{a}$ \\
\hline Hexyl acetate & 1285 & A & Fruit, herb & $33,117 \pm 406^{b}$ & $31,075 \pm 3041^{\mathrm{b}}$ & $4638 \pm 1159^{a}$ \\
\hline o-Cymene & 1304 & B & $\mathrm{ni}^{* * * *}$ & $21,481 \pm 4833^{a}$ & $16,599 \pm 6054^{a}$ & $22,477 \pm 1645^{a}$ \\
\hline Hexanol & 1375 & A & Resin, flower, green & $143,011 \pm 4460^{b}$ & $59,447 \pm 5744^{a}$ & $143,492 \pm 952^{b}$ \\
\hline Allo-Ocimene & 1361 & B & ni & $62,984 \pm 2685^{b}$ & $25,507 \pm 4448^{a}$ & $28,304 \pm 8494^{a}$ \\
\hline Methyl octanoate & 1401 & A & Orange & $62,986 \pm 20,828^{b}$ & $27,717 \pm 1175^{a b}$ & $\mathrm{nd}^{\mathrm{a}}$ \\
\hline (Z)-3-Hexenol & 1410 & A & Moss, fresh & $70,052 \pm 5286^{c}$ & $4544 \pm 1290^{\mathrm{a}}$ & $43,789 \pm 1585^{b}$ \\
\hline Ethyl octanoate & 1437 & $\mathrm{~A}$ & Fruit, fat & $329,393 \pm 12,672^{b}$ & $10,942 \pm 284^{\mathrm{a}}$ & $15,176 \pm 1598^{a}$ \\
\hline Cyclosativene & 1481 & $\mathrm{~B}$ & ni & $35,162 \pm 2860^{b}$ & nd $^{\mathrm{a}}$ & nd $^{\mathrm{a}}$ \\
\hline Methyl decanoate & 1602 & A & wine & $81,464 \pm 27,691^{b}$ & $41,379 \pm 5233^{a}$ & $8252 \pm 497^{\mathrm{a}}$ \\
\hline Ethyl decanoate & 1647 & A & grape & $158,110 \pm 38,375^{c}$ & nd $^{\mathrm{a}}$ & $12,027 \pm 2527^{b}$ \\
\hline Methyl benzoate & 1656 & A & $\begin{array}{l}\text { Prune, lettuce, } \\
\text { herb, sweet }\end{array}$ & $155,0154 \pm 481,956^{b}$ & $48,103 \pm 6285^{a}$ & $175,374 \pm 15,723^{a}$ \\
\hline Methyl salicylate & 1795 & A & Peppermint & $6,075,487 \pm 797,505^{b}$ & $50,712 \pm 10,993^{a}$ & $298,455 \pm 82,070^{a}$ \\
\hline
\end{tabular}

* For identification (ID), A stands for mass spectrum and RI agreeing with standards, and B stands for mass spectrum agreeing with mass spectral data base and RI agreeing with the literature data. ** Aromatic description was performed using Flavornet [27], Pherobase [28] and NIST Mass Spectrometry Data Center [29]. *** Different letters indicate significant differences among the hybrids for a particular VOC using ANOVA, followed by a Fisher LSD test $(p \leq 0.05) .{ }^{* * *}$ nd stands for 'not detected' and ni stands for 'no information'.

Considering the amount of the VOCs detected, monoterpenes and esters dominated the floral scent composition of the alstroemeria hybrids analysed. Thus, the total sum of the peak areas of the monoterpenes detected in the hybrid 13M07 $(1,831,922)$ was significantly higher compared to the hybrids 13B01 $(811,528)$ and 14E07 $(1,004,811)$. Moreover, the total sum of esters peak areas detected in the hybrids 13B01 $(242,360)$ and 14E07 $(527,478)$ was almost insignificant compared to the high accumulation of these compounds detected in 13M07 $(8,337,863)$ (Figure 2). In general, detection of alcohols was lower compared to monoterpenes and esters. In this case, their higher presence was detected in the scented hybrids 13M07 $(213,062)$ and 14E07 $(187,280)$, compared to non-scented 13B01 $(63,990)$ (data not shown).

From the differences observed among the hybrids in terms of the amounts of VOCs, the esters methyl salicylate and methyl benzoate were particularly significant. In both cases, these esters showed a clearly higher abundance in the hybrid 13M07 with abundance values up to 32 and 119 times higher for methyl benzoate and methyl salicylate, respectively (Figure 3). 


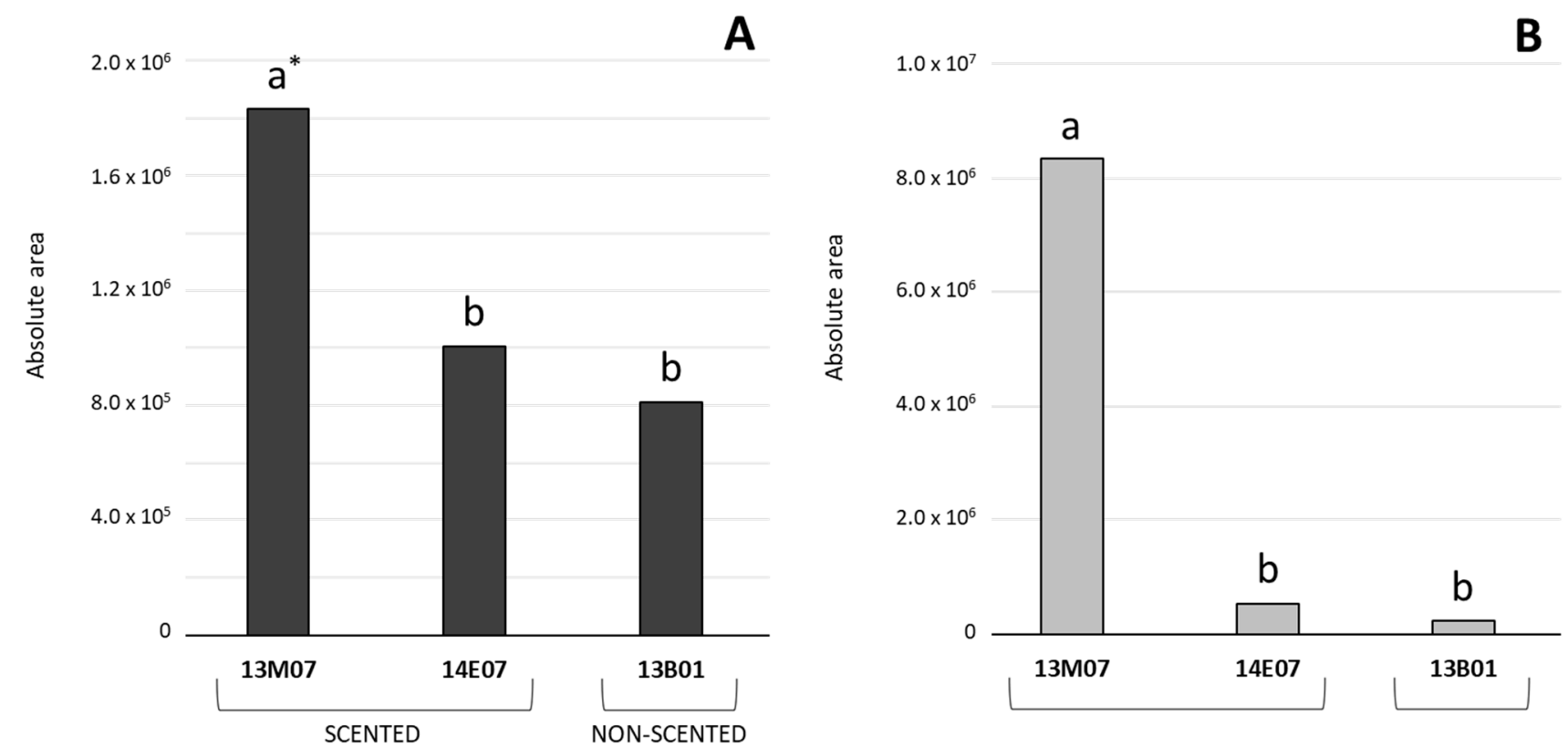

Figure 2. Comparison of the peak areas $( \pm \mathrm{SE}, n=3)$ calculated for monoterpenes $(\mathbf{A})$ and esters (B), detected in the flowers of the scented hybrids 13M07 and 14E07, and the non-scented 13B01. * Different letters indicate significant differences among the hybrids for the sum total of monoterpenes and esters using ANOVA, followed by a Fisher LSD test $(p \leq 0.05)$.

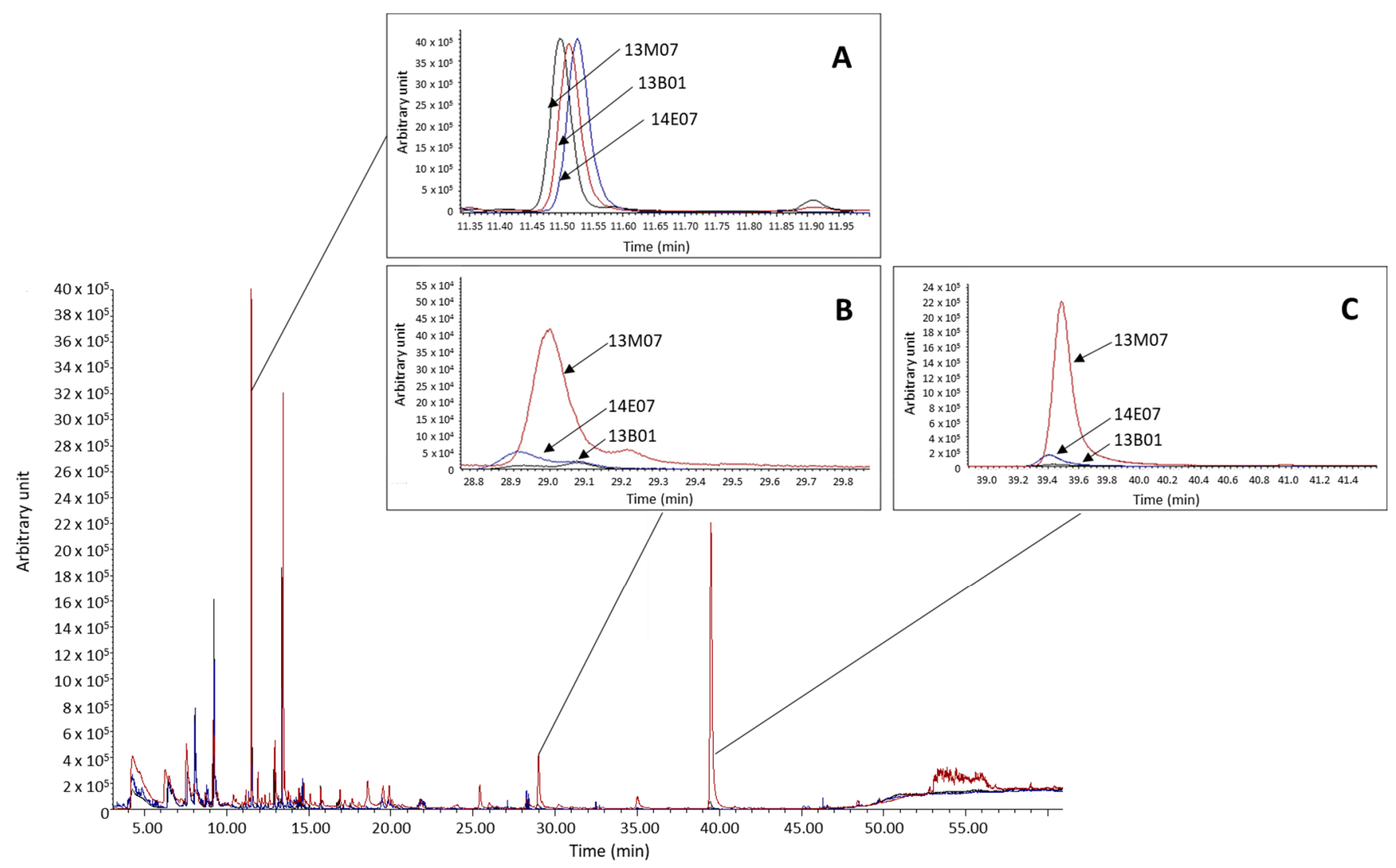

Figure 3. Overlay of chromatograms of each sample and comparison of the abundance of the internal standard (A) and the esters methyl benzoate (B) and methyl salicylate (C), detected in the flowers of the scented hybrids 13M07 and 14E07, and the non-scented 13B01. 


\section{Discussion}

\subsection{Sensorial Analysis}

In the sensorial analysis, two alstroemeria hybrids were consistently perceived as scented (13M07 and 14E07). However, a significant effect of the stage of development and the time of evaluation on this perception was observed. Previous reports have identified anthesis as the stage of maximum scent output [13]. This is clearly linked to the attraction of pollinators, and specifically for alstroemeria, since stages 4 and 5 were described as the peak of scent output for this species [24]. While flowers of the 13M07 hybrid were perceived as scented at the three times of evaluation, 14E07 was only perceived as scented during the afternoon. Evaluations early in the morning and late afternoon/night were not considered in this study, as preliminary assessments showed no scent output at those times. Moreover, alstroemeria has been reported as being pollinated mainly by diurnal insects such as flies [30] and hymenopters [31]. Furthermore, the fact that maximum scent output was detected around 1:00 p.m. and 4:00 p.m. could also be related to environmental factors such as temperature [12] and light [11], both of which have also been related to floral scent emission.

The highest scent intensity was perceived from flowers of the hybrid 14E07 (7.11) in comparison with 13M07 (3.58) (Table 1). However, a greater number of VOCs (19) and higher absolute areas calculated for monoterpenes $(1,831,922)$ and esters $(8,337,863)$ were observed in the hybrid 13M07. This result confirmed that perception of floral scent is not directly related to the abundance of VOCs [17] because interaction between odour receptor and chemical compounds is rather complex and still poorly understood [32].

\subsection{Analysis of $V O C s$}

VOC detection and semi-quantification in terms of absolute areas showed significant differences between the three hybrids analysed. These differences cannot be attributed to the intensity, the presence, or the absence of the character of the scent. Thus, the nonscented 13B01 and the scented 14E07 did not show differences in terms of absolute areas calculated for monoterpenes and esters, while the more intensely scented hybrid 14E07 showed lower absolute areas calculated for these compounds than the less intensely scented 13M07 (Figure 2).

\subsection{Ocimene Isomers}

Three out of the four ocimene isomers detected ((Z)-Ocimene, (E)-Ocimene and oCymene) did not show significant differences, in terms of absolute areas, between the scented (14E07 and 13M07) and the non-scented (13B01) hybrids. Monoterpenes, particularly ocimene isomers, have been strongly associated with multiple interactions between plants and other organisms [33]. In this study, (E)-Ocimene was detected in all the hybrids evaluated. A previous study also reported this monoterpene in alstroemeria hybrids as the major VOC detected [25]. (E)- $\beta$-ocimene is a very common VOC present in the floral scent of a wide range of species [14]. In a more recent review, (E)- $\beta$-ocimene was identified in the floral scents of $47.5 \%$ of the 291 plant species and in $75.0 \%$ of the 63 plant families analysed [30]. Furthermore, this compound has been reported to be emitted at a high concentration from insect-damaged plants of Medicago truncatula [34] and Lotus japonicus [35]. Its abundance has been linked to its role in the attraction of different pollinators, including beetles [36], butterflies [37] and bees [38]. Therefore, the presence of these monoterpenes in the floral scent of a non-scented alstroemeria hybrid, which are perceived by insects but not by our human olfactory system, can be attributed to their ecological role, even though these compounds are normally described as showing a very low odour detection threshold (ODT) [39].

\subsection{Monoterpenes}

Significantly higher values of absolute peak areas of the monoterpenes $\beta$-pinene, D-limonene and eucalyptol were detected in the scented hybrids in comparison with the 
non-scented plants, suggesting that perhaps those compounds are part of the floral scent detected through the sensorial analysis. These compounds have been previously detected in Alstroemeria caryophyllaea Jacq. [16,24] and alstroemeria hybrids [25]. $\beta$-pinene is one of the most common monoterpenes found in floral scents [31], and has been detected as the major VOC in species like Magnolia grandiflora L. [40], chrysanthemum [17] and Citrus grandis Osbeck [41]. Moreover, this monoterpene has been associated with a pleasant odour perceived in orange juice [42]. D-limonene is one of the most common terpenes found in nature. It is mainly associated with citrus oils [43] and detected through sensorial evaluation of orange juice [44]. Eucalyptol, known also as 1,8-cineole, is a cyclic monoterpene has been detected previously as a major compound in flowers of oriental $\times$ trumpet hybrid lilies [45] and Laurus nobilis L. [46] and as an important aroma constituent of strawberry and lemon guava (Psidium cattleianum Sabine) juice [47]. Both D-limonene and eucalyptol have been identified as major VOCs in some tulip varieties clustered in the group 'herbal' according to their floral scent [48]. Thus, these three monoterpenes, detected with significantly higher values of absolute peak areas in the scented hybrids, possibly contribute to the floral scent of alstroemeria perceived in sensorial analysis, and, considering previous reports and the low ODT these VOCs normally present, particularly eucalyptol and D-limonene [48,49].

\subsection{Esters}

Methyl salicylate and methyl benzoate were detected in all three alstroemeria hybrids but at higher values of absolute peak areas in 13M07. This is the first report of these esters as part of the floral scent of alstroemeria, as previous studies performed on the floral scent of this species detected mostly terpenoid compounds $[16,24,25]$. The most likely reason why these compounds were detected as major VOCs for this species is the fact that different alstroemeria genotypes were assessed. However, the application of a different method and the use of a different equipment could also explain this result. Both esters are biosynthesized by the action of carboxyl methyltransferases and have been associated not only with the attraction of pollinators [50], but also play an important role as airborne signals intervening in inter and intra-plant communication to activate disease resistance [51]. Methyl salicylate was the number one VOC for the hybrid 13M07 and the number two VOC for 14E07, both of which are scented hybrids. This compound has been identified as the main contributor to 'spicy' and 'sweet' odour in the floral scent of tulips [46] and to 'sweet' and 'medicinal' fragrance in Dianthus species [52]. Both esters could, therefore, be part of the fragrance perceived by the evaluators from the scented alstroemeria hybrids assessed. Moreover, it is possible that the floral scent was perceived as a bouquet [25], considering the major compounds for each scented hybrid, but together with other VOCs.

\subsection{Floral Scent Differences between Scented Hybrids}

Finally, it is remarkable that two hybrids coming from the same parental lines (A. pelegrina $\times$ A. hybrid '0276-02' (Figure 1) showed different VOC profiles, particularly in terms of absolute areas, with significant differences for monoterpenes and esters (Figure 2), and sensorially in terms of intensity (Table 1). The diversity of floral scent patterns of seedlings was previously observed in Dianthus spp. [52] Cymbidium spp. [53] and alstroemeria [25]. Furthermore, the heredity of floral scent has been described to be complicated, as floral scent is easily gained and lost throughout generations [22] given the complexity of the biosynthetic pathway of VOC and the intricate composition of the aroma [10].

\section{Conclusions}

The diversity and amounts of VOCs detected in alstroemeria are probably related to the ecological role of floral scent. On the other hand, this VOC profile seems to be rather irrelevant to human perception of floral scent since VOCs differences observed between scented and non-scented hybrids were not strictly related to the sensory results. Further studies could be focused on how pollinator behaviour is related to the floral scent profile 
described in this study. Furthermore, we can confirm the complexity this trait shows for phenotyping studies, generating a big challenge, for example, when using floral scent as a selection character in a breeding programme.

It is also important to highlight that for the first time two esters (methyl benzoate and methyl salicylate) were detected in the floral scent of alstroemeria, since all the previous literature reported mainly terpenoid compounds. This discovery could open a new research line focused on the biosynthesis pathway of these compounds, and towards the identification of new genes related the floral scent in alstroemeria, considering the importance of this character in the flower market.

Author Contributions: Conceptualization, D.A. and C.U.; methodology, D.A., C.U. and M.M.; formal analysis, M.S., D.A. and C.U.; data curation, M.S.; investigation, M.S. and C.U.; writing-original draft preparation, D.A., C.U. and M.S.; writing-review and editing, D.A., C.U. and M.M.; visualization, D.A., C.U. and M.M.; supervision, D.A., C.U. and M.M.; project administration, D.A.; funding acquisition, D.A. All authors have read and agreed to the published version of the manuscript.

Funding: This research was funded by FONDECYT Initiation into Research Nº11130325 and FONDEQUIP NEQ130129, Government of Chile.

Acknowledgments: The authors also want to give thanks to the VI Plan Propio de Investigación y Transferencia of the University of Seville for Cristina Ubeda current contract (Contract number USE-18644-Z) and to J. Hurley and M. López for the English language editing of this manuscript.

Conflicts of Interest: The authors declare no conflict of interest.

\section{Appendix A}

Table A1. Averages obtained for the sensorial analysis of floral scent perceived in alstroemeria hybrids (yes $=1$ and no $=0$ ) at different stages of development and different times of evaluation.

\begin{tabular}{ccccccc}
\hline \multirow{2}{*}{ Hybrid } & \multicolumn{3}{c}{ Stage of Development } & \multicolumn{3}{c}{ Time of Evaluation } \\
\cline { 2 - 7 } & S3 & S4 & S5 & $\mathbf{1 0 : 0 0 ~ h}$ & $\mathbf{1 3 : 0 0 ~ h}$ & $\mathbf{1 6 : 0 0 ~ h}$ \\
\hline 13A01 & 0.00 & 0.00 & 0.00 & 0.00 & 0.00 & 0.17 \\
13B01 & 0.00 & 0.00 & 0.00 & 0.00 & 0.00 & 0.27 \\
13B04 & 0.00 & 0.00 & 0.00 & 0.00 & 0.21 & 0.00 \\
13B07 & 0.00 & 0.52 & 0.00 & 0.00 & 0.00 & 0.21 \\
13B11 & 0.17 & 0.00 & 0.00 & 0.00 & 0.00 & 0.00 \\
13E01 & 0.17 & 0.00 & 0.00 & 0.00 & 0.00 & 0.32 \\
13M07 & 0.50 & 0.68 & 0.68 & 0.50 & 0.61 & 0.75 \\
14A11 & 0.00 & 0.00 & 0.00 & 0.00 & 0.00 & 0.00 \\
14B01 & 0.00 & 0.00 & 0.00 & 0.00 & 0.00 & 0.00 \\
14D01 & 0.00 & 0.00 & 0.00 & 0.00 & 0.00 & 0.32 \\
14D19 & 0.00 & 0.00 & 0.00 & 0.00 & 0.00 & 0.00 \\
14E06 & 0.00 & 0.00 & 0.00 & 0.00 & 0.00 & 0.21 \\
14E07 & 0.00 & 1.00 & 0.68 & 0.00 & 0.50 & 1.00 \\
14E08 & 0.00 & 0.00 & 0.00 & 0.00 & 0.00 & 0.00 \\
14F02 & 0.00 & 0.00 & 0.00 & 0.00 & 0.00 & 0.00 \\
14H03 & 0.00 & 0.00 & 0.00 & 0.00 & 0.00 & 0.00 \\
ALIG & 0.17 & 0.17 & 0.00 & 0.00 & 0.17 & 0.00 \\
APEL & 0.00 & 0.00 & 0.00 & 0.00 & 0.00 & 0.00 \\
\hline
\end{tabular}




\section{Appendix B}

\begin{tabular}{|c|c|c|}
\hline Stage & Description & Picture \\
\hline SO & Coloured bud & \\
\hline S1 & First tepal opening & \\
\hline S2 & Full flower opening & \\
\hline S3 & Three dehiscent anthers & \\
\hline S4 & Six dehiscent anthers & \\
\hline S5 & $\begin{array}{l}\text { Stigma opening and } \\
\text { stigmatic liquid on the top }\end{array}$ & \\
\hline S6 & $\begin{array}{l}\text { Loss of colour and starting } \\
\text { of wilt on tepals }\end{array}$ & \\
\hline S7 & Falling of wilted tepals & \\
\hline
\end{tabular}

Figure A1. Description of the stages of development observed in alstroemeria, from stage 0 (S0) to 7 (S7) according to Wagstaff et al. (2001). Pictures provided correspond to A. caryophyllaea Jacq.

\section{References}

1. Dudareva, N.; Pichersky, E. Biology of Floral Scent; CRC Press: Boca Raton, FL, USA, 2006; 364p.

2. Fenster, C.B.; Armbruster, W.S.; Wilson, P.; Dudash, M.R.; Thomson, J.D. Pollination syndromes and floral specialization. Annu. Rev. Ecol. Evol. Syst. 2004, 35, 375-403. [CrossRef]

3. Raguso, R.A. Wake up and smell the roses: The ecology and evolution of floral scent. Annu. Rev. Ecol. Evol. Syst. 2008, 39, 549-569. [CrossRef]

4. Junker, R.R.; Parachnowitsch, A.L. Working towards a holistic view on flower traits-how floral scents mediate plant-animal interactions in concert with other floral characters. J. Indian Inst. Sci. 2015, 95, 43-68.

5. Dudareva, N.; Pichersky, E. Biochemical and molecular genetic aspects of floral scents. Plant Physiol. 2000, 122, 627-634. [CrossRef] 
6. De Moraes, C.M.; Mescher, M.C.; Tumlinson, J.H. Caterpillar-induced nocturnal plant volatiles repel conspecific females. Nature 2001, 410, 577-580. [CrossRef]

7. Friedman, M.; Henika, P.R.; Mandrell, R.E. Bactericidal activities of plant essential oils and some of their isolated constituents against Campylobacter jejuni, Escherichia coli, Listeria monocytogenes, and Salmonella enterica. J. Food Prot. 2002, 65, 1545-1560. [CrossRef]

8. Hammer, K.A.; Carson, C.F.; Riley, T.V. Antifungal activity of the components of Melaleuca alternifolia (tea tree) oil. J. Appl. Microbiol. 2003, 95, 853-860. [CrossRef]

9. Caruso, C.M.; Parachnowitsch, A.L. Do plants eavesdrop on floral scent signals? Trends Plant Sci. 2016, 21, 9-15. [CrossRef]

10. Schnepp, J.; Dudareva, N. Floral scent: Biosynthesis, regulation and genetic modifications. Flower. Its Manip. $2018,10,240-257$.

11. Hu, Z.; Zhang, H.; Leng, P.; Zhao, J.; Wang, W.; Wang, S. The emission of floral scent from Lilium 'Siberia' in response to light intensity and temperature. Acta Physiol. Plant. 2013, 35, 1691-1700. [CrossRef]

12. Fu, J.; Hou, D.; Zhang, C.; Bao, Z.; Zhao, H.; Hu, S. The emission of the floral scent of four Osmanthus fragrans cultivars in response to different temperatures. Molecules 2017, 22, 430. [CrossRef] [PubMed]

13. Farré-Armengol, G.; Filella, I.; Llusià, J.; Peñuelas, J. Pollination mode determines floral scent. Biochem. Syst. Ecol. 2015, 61, 44-53. [CrossRef]

14. Knudsen, J.T.; Eriksson, R.; Gershenzon, J.; Ståhl, B. Diversity and distribution of floral scent. Bot. Rev. 2006, 72, 1. [CrossRef]

15. Kim, S.Y.; An, H.R.; Park, P.M.; Baek, Y.S.; Kwon, O.K.; Park, S.Y.; Park, P.H. Analysis of floral scent patterns in flowering stages and floral organs of Maxillaria using an electronic nose. Flower Res. J. 2016, 24, 171-180. [CrossRef]

16. Aros, D.; Spadafora, N.; Venturi, M.; Núñez-Lillo, G.; Meneses, C.; Methven, L.; Müller, C.; Rogers, H. Floral scent evaluation of segregating lines of Alstroemeria caryophyllaea. Sci. Hortic. 2015, 185, 183-192. [CrossRef]

17. Aros, D.; Garrido, N.; Rivas, C.; Medel, M.; Müller, C.; Rogers, H.; Úbeda, C. Floral scent evaluation of three cut flowers through sensorial and gas chromatography analysis. Agronomy 2020, 10, 131. [CrossRef]

18. Finot, V.; Baeza, C.; Muñoz-Schick, M.; Ruiz, E.; Espejo, J.; Alarcón, D.; Carrasco, P.; Novoa, P.; Eyzaguirre, M.T. Guía de Campo Alstroemerias Chilenas; Corporación Chilena de la Madera: Concepción, Chile, 2018; 292p.

19. Assis, M.C. Alstroemeriaceae no estado do Rio de Janeiro. Rodriguésia 2004, 55, 19-26. [CrossRef]

20. Lim, S.S.; Lee, S.I.; Kang, S.C.; Kim, J.B. Alstroemeria plants and its biotechnological applications. J. Plant Biotechnol. 2012, 39, 219-224. [CrossRef]

21. Bridgen, M.P. Alstroemeria. In Ornamental Crops; Springer: Berlin/Heidelberg, Germany, 2018; pp. $231-236$.

22. Amrad, A.; Moser, M.; Mandel, T.; de Vries, M.; Schuurink, R.C.; Freitas, L.; Kuhlemeier, C. Gain and loss of floral scent production through changes in structural genes during pollinator-mediated speciation. Curr. Biol. 2016, 26, 3303-3312. [CrossRef]

23. Borda, A.M.; Clark, D.G.; Huber, D.J.; Welt, B.A.; Nell, T.A. Effects of ethylene on volatile emission and fragrance in cut roses: The relationship between fragrance and vase life. Postharvest Biol. Technol. 2011, 59, 245-252. [CrossRef]

24. Aros, D.; Gonzalez, V.; Allemann, R.K.; Müller, C.T.; Rosati, C.; Rogers, H.J. Volatile emissions of scented Alstroemeria genotypes are dominated by terpenes, and a myrcene synthase gene is highly expressed in scented Alstroemeria flowers. J. Exp. Bot. 2012, 63, 2739-2752. [CrossRef]

25. Aros, D.; Suazo, M.; Rivas, C.; Zapata, P.; Ubeda, C.; Bridgen, M. Molecular and morphological characterization of new interspecific hybrids of alstroemeria originated from A. caryophylleae scented lines. Euphytica 2019, 215, 93. [CrossRef]

26. Wagstaff, C.; Rogers, H.J.; Leverentz, M.; Thomas, B.; Chanasut, U.; Stead, A. Characterisation of Alstroemeria vase life. Acta Hortic. 2001, 543, 161-175. [CrossRef]

27. Flavornet and Human Odor Space. Available online: http:/ flavornet.org/ (accessed on 8 April 2020).

28. The Pherobase: Database of Pheromones and Semiochemicals. Available online: https://www.pherobase.com/ (accessed on 8 April 2020).

29. The National Institute of Standards and Technology (NIST) Mass Spectrometry Data Center. Available online: https://chemdata nist.gov/ (accessed on 8 April 2020).

30. González, A.V.; Murúa, M.; Ramírez, P.A. Temporal and spatial variation of the pollinator assemblages in Alstroemeria ligtu (Alstroemeriaceae). Rev. Chil. De Hist. Nat. 2014, 87, 5. [CrossRef]

31. Aizen, M.A.; Basilio, A. Sex differential nectar secretion in protandrous Alstroemeria aurea (Alstroemeriaceae): Is production altered by pollen removal and receipt? Am. J. Bot. 1998, 85, 245-252. [CrossRef] [PubMed]

32. Zarzo, M. The sense of smell: Molecular basis of odorant recognition. Biol. Rev. 2007, 82, 455-479. [CrossRef]

33. Farré-Armengol, G.; Filella, I.; Llusià, J.; Peñuelas, J. $\beta$-Ocimene, a key floral and foliar volatile involved in multiple interactions between plants and other organisms. Molecules 2017, 22, 1148. [CrossRef]

34. Navia-Giné, W.G.; Yuan, J.S.; Mauromoustakos, A.; Murphy, J.B.; Chen, F.; Korth, K.L. Medicago truncatula (E)- $\beta$-ocimene synthase is induced by insect herbivory with corresponding increases in emission of volatile ocimene. Plant Physiol. Biochem. 2009, 47, 416-425. [CrossRef]

35. Arimura, G.I.; Ozawa, R.; Kugimiya, S.; Takabayashi, J.; Bohlmann, J. Herbivore-induced defense response in a model legume Two-spotted spider mites induce emission of (E)- $\beta$-ocimene and transcript accumulation of (E)- $\beta$-ocimene synthase in Lotus japonicus. Plant Physiol. 2004, 135, 1976-1983. [CrossRef]

36. Dufaÿ, M.; Hossaert-McKey, M.; Anstett, M.C. When leaves act like flowers: How dwarf palms attract their pollinators. Ecol. Lett. 2003, 6, 28-34. [CrossRef] 
37. Andersson, S.; Nilsson, L.A.A.; Groth, I.; Bergstrom, G. Floral scents in butterfly-pollinated plants: Possible convergence in chemical composition. Bot. J. Linn. Soc. 2002, 140, 129-153. [CrossRef]

38. Borg-Karlson, A.-K.; Valterová, I.; Nilsson, L.A. Volatile compounds from flowers of six species in the family Apiaceae: Bouquets for different pollinators? Phytochemistry 1994, 35, 111-119. [CrossRef]

39. Tamura, H.; Boonbumrung, S.; Yoshizawa, T.; Varanyanond, W. The volatile constituents in the peel and pulp of a green Thai mango, Khieo Sawoei cultivar (Mangifera indica L.). Food Sci. Technol. Res. 2001, 7, 72-77. [CrossRef]

40. Báez, D.; Pino, J.A.; Morales, D. Volatiles from Magnolia grandiflora flowers: Comparative analysis by simultaneous distillationextraction and solid phase microextraction. Nat. Prod. Commun. 2012, 7, 237-238. [CrossRef]

41. Huang, H.H.; Lin, L.Y.; Chiang, H.M.; Lay, S.J.; Wu, C.S.; Chen, H.C. Analysis of volatile compounds from different parts of Citrus grandis (L.) Osbeck flowers by headspace solid-phase microextraction-gas chromatography-mass spectrometry. J. Essent. Oil Bear. Plants 2017, 20, 1057-1065. [CrossRef]

42. Kim, M.K.; Jang, H.W.; Lee, K.G. Sensory and instrumental volatile flavor analysis of commercial orange juices prepared by different processing methods. Food Chem. 2018, 267, 217-222. [CrossRef] [PubMed]

43. Sun, J. D-Limonene: Safety and clinical applications. Altern. Med. Rev. 2007, 12, 259-264.

44. Rodríguez, A.; Peris, J.E.; Redondo, A.; Shimada, T.; Costell, E.; Carbonell, I.; Rojas, C.; Peña, L. Impact of D-limonene synthase up-or down-regulation on sweet orange fruit and juice odor perception. Food Chem. 2017, 217, 139-150. [CrossRef] [PubMed]

45. Kong, Y.; Sun, M.; Pan, H.T.; Zhang, Q.X. Composition and emission rhythm of floral scent volatiles from eight lily cut flowers. J. Am. Soc. Hortic. Sci. 2012, 137, 376-382. [CrossRef]

46. Kilic, A.; Hafizoglu, H.; Kollmannsberger, H.; Nitz, S. Volatile constituents and key odorants in leaves, buds, flowers, and fruits of Laurus nobilis L. J. Agric. Food Chem. 2004, 52, 1601-1606. [CrossRef]

47. Egea, M.B.; Pereira-Netto, A.B.; Cacho, J.; Ferreira, V.; Lopez, R. Comparative analysis of aroma compounds and sensorial features of strawberry and lemon guavas (Psidium cattleianum Sabine). Food Chem. 2014, 164, 272-277. [CrossRef] [PubMed]

48. Oyama-Okubo, N.; Tsuji, T. Analysis of floral scent compounds and classification by scent quality in tulip cultivars. J. Jpn. Soc. Hortic. Sci. 2013, 82, 344-353. [CrossRef]

49. Fariña, L.; Boido, E.; Carrau, F.; Versini, G.; Dellacassa, E. Terpene compounds as possible precursors of 1,8-cineole in red grapes and wines. J. Agric. Food Chem. 2005, 53, 1633-1636. [CrossRef] [PubMed]

50. Negre, F.; Kolosova, N.; Knoll, J.; Kish, C.M.; Dudareva, N. Novel S-adenosyl-L-methionine: Salicylic acid carboxyl methyltransferase, an enzyme responsible for biosynthesis of methyl salicylate and methyl benzoate, is not involved in floral scent production in snapdragon flowers. Arch. Biochem. Biophys. 2002, 406, 261-270. [CrossRef]

51. Shulaev, V.; Silverman, P.; Raskin, I. Airborne signalling by methyl salicylate in plant pathogen resistance. Nature 1997, 385, 718-721. [CrossRef]

52. Kishimoto, K.; Nakayama, M.; Yagi, M.; Onozaki, T.; Oyama-Okubo, N. Evaluation of wild dianthus species as genetic resources for fragrant carnation breeding based on their floral scent composition. J. Jpn. Soc. Hortic. Sci. 2011, 80, 175-181. [CrossRef]

53. Park, P.H.; Ramya, M.; An, H.R.; Park, P.M.; Lee, S.Y. Breeding of Cymbidium 'Sale Bit' with bright yellow flowers and floral scent. Korean Soc. Breed. Sci. 2019, 51, 258-262. [CrossRef] 